\title{
Thermodynamics and Phase Behavior of Block Copolymer/Homopolymer Blends with Attractive and Repulsive Interactions
}

\author{
J. H. Lee \\ Department of Chemical Engineering, University of California, Berkeley, California 94720
}

\section{N. P. Balsara* and A. K. Chakraborty}

Department of Chemical Engineering and Materials Sciences Division, Lawrence Berkeley National Laboratory, University of California, Berkeley, California 94720

\section{R. Krishnamoorti}

Department of Chemical Engineering, University of Houston, Houston, Texas 77204

\section{B. Hammouda}

National Institute of Standards and Technology, Building 235, E 151, Gaithersburg, Maryland 20899 Received March 8, 2002

\begin{abstract}
Small-angle neutron scattering (SANS) experiments were conducted on a 25 vol \% blend of a poly(ethylene-block-head-to-head propylene) copolymer (PE - PP) in polyisobutylene (PIB). PE/PIB and $\mathrm{PE} / \mathrm{PP}$ chains are incompatible (the Flory-Huggins interaction parameter $\chi>0$ ), while PIB and PP are compatible $(\chi<0)$ at low temperatures and incompatible $(\chi>0)$ at high temperatures. These interactions lead to an order-disorder transition at $150 \pm 5^{\circ} \mathrm{C}$ and macrophase separation at $251 \pm 5^{\circ} \mathrm{C}$. The nature of the concentration fluctuations in the homogeneous state $\left(155^{\circ} \mathrm{C}<\mathrm{T}<246{ }^{\circ} \mathrm{C}\right)$ was studied by comparing the experimentally determined SANS profiles with theoretical calculations based on the multicomponent random phase approximation (RPA). Order formation at low temperatures is driven by two parameters: $\chi_{\mathrm{PE} / \mathrm{PIB}}$ and $\mathrm{I}_{\mathrm{PP}}$ (the statistical segment length of the PP block). The other temperature-dependent parameters drive the system away from the ordering transition. At high temperatures, the RPA predicts microphase separation, while experimental data (neutron and light scattering) indicate macrophase separation. This discrepancy is mainly due to the inability of the RPA to correctly account for the large length scale concentration fluctuations.
\end{abstract}

\section{Introduction}

Polymer blends are excellent model systems for fundamental studies of liquid state thermodynamics. ${ }^{1-10}$ Predicting the thermodynamic properties of individual chains requires knowledge of two parameters: the statistical segment length, I, which accounts for local intrachain correlations on the monomer length scale, and the chain length, $\mathrm{N}$ (number of monomers per chain), which characterizes the large length scale properties of the chains. The interactions between different chains are characterized by a Flory-Huggins interaction parameter, $\chi$. Knowledge of these parameters $(\chi, N$, and I) enables prediction of the thermodynamic properties of any multicomponent mixture in the mean-fiel d limit, regardless of the intricacy of molecular architecture (e.g., star block copolymers) and compl exity of phase behavior (e.g., polymer-in-polymer mi croemulsions). ${ }^{11}$ There are, however, three outstanding problems: (1) In many systems, the $\chi$ parameters depend on blend composition in an unpredictable way. ${ }^{7,12}(2)$ In complex, multicomponent systems characterized by a multitude of $\chi$ parameters, chain lengths, and statistical segment lengths, methods for identifying the subset of parameters that govern the thermodynamics of mixing have not been established. (3) The presence of large concentration fluctuations leads to departures from mean-field behavior, and such effects have only been studied in a few systems. ${ }^{13,14}$

Considerable work has been done on binary and multicomponent blends between polymers with repul- sive interactions $(\chi>0) .{ }^{15-27}$ There is, however, an increasing interest in block copolymer/homopolymer blends wherein the $\chi$ parameters are both positive and negative. In this paper we focus on $A-B / C$ diblock copolymer/homopolymer blends wherein $\chi_{\mathrm{AC}}$ is positive and a decreasing function of temperature, while $\chi_{\mathrm{BC}}$ is negative and an increasing function of temperature. In other words, A/C interactions are repulsive while B/C interactions are attractive in the temperature range of interest. Hashimoto et al. studied poly(styrene-blockisoprene)/poly(phenylene oxide) and poly(styrene-blockbutadiene)/poly(methyl vinyl ether) blends, wherein the homopolymers exhibit negative $\chi$ parameters with polystyrene. ${ }^{28,29}$ They used electron microscopy to demonstrate a rich variety of ordered phases and the coexistence of different ordered phases. J amieson, Hudson, and co-workers ${ }^{30}$ found that the addition of polystyrenepoly(methyl methacrylate) (PS-PMMA) block copolymers led to the development of phase-inverted morphologies in mixtures of a styrene-acryl onitrile copolymer (SAN) and polystyrene (PS). This unusual morphology was attributed to the negative $\chi$ parameter between SAN and PMMA. This results in a swollen PMMA block, which, in turn, leads to interfaces curving toward the polystyrene phase. Similar systems were studied by Lowenhaupt et al., who showed the coexistence of macrophases and microphases. ${ }^{24,25}$ All of the experimental results discussed here on $A-B / C$ blends $24,25,28-30$ are based on observations of phase behavior by electron microscopy. 
Table 1. Characteristics of Components

\begin{tabular}{lccccc}
\hline component & $\begin{array}{c}\text { weight-average } \\
\text { mol wt }(\mathrm{kg} / \mathrm{mol})\end{array}$ & polydispersity index & $\begin{array}{c}\text { density at } 23{ }^{\circ} \mathrm{C} \\
\left(\mathrm{g} / \mathrm{cm}^{3}\right)\end{array}$ & $\begin{array}{c}\text { vol fraction of PE in } \\
\text { block copolymer }\end{array}$ & $\begin{array}{c}\text { av no. of deuterium } \\
\text { per } \mathrm{C}_{4} \text { monomer }\end{array}$ \\
\hline $\mathrm{dPE}-\mathrm{dPP}$ & 66 & 1.12 & 0.9476 & 0.49 & 3.19 \\
$\mathrm{PIB}$ & 14 & 1.15 & 0.918 & & 0
\end{tabular}

$$
\left.-\mathrm{CH}_{2}-\mathrm{CH}_{2}-\mathrm{CH}_{2}-\mathrm{CH}_{2}\right]_{\mathrm{n}}\left[\begin{array}{c}
\mathrm{CH}_{2}-\underset{\mathrm{CH}}{\mathrm{C}}-\underset{\mathrm{CH}}{\mathrm{C}}-\mathrm{CH}_{2} \\
\mathrm{CH}_{3} \mathrm{CH}_{3}
\end{array}\right]_{\mathrm{m}}
$$

poly(ethylene-b-head-to-head propylene) copolymer (PE-PP)

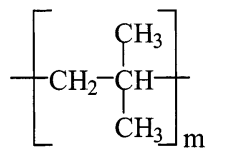

polyisobutylene (PIB)

Figure 1. Chemical structures of poly(ethylene-block-headto-head propylene) (PE-PP) and polyisobutylene (PIB) chains. The deuterium labels on the PE -PP copolymer are not shown.

There are important connections between phase behavior and pretransitional concentration fluctuations. These fluctuations are announcements of the nature of impending phase transitions. This has been exploited in studies of binary homopolymer blends, block copolymer melts, and mixtures thereof. ${ }^{2-10,31-37}$ The purpose of this paper is to study both pretransitional concentration fluctuations and phase behavior in $\mathrm{A}-\mathrm{B} / \mathrm{C}$ mixtures with both attractive and repulsive interactions. The specific system studied in this paper is a blend of poly(ethylene-bl ock-head-to-head propylene) copolymer (PEPP) and a polyisobutylene homopolymer (PIB). The $\chi$ parameter between PIB and PP chains is negative, while the other $\chi$ parameters are positive. ${ }^{37,38}$

This paper is part of a series on the subject of concentration fluctuations and phase behavior of complex polymer blends. ${ }^{33-37}$ Most of our previous work $33,34,36,37$ is restricted to blends with repulsive interactions only. In a recent paper we studied blends of polyisobutylene (PIB), polyethylene (PE), and a poly(ethylene-bl ock-head-to-head propylene) copolymer (PEPP). ${ }^{35}$ The PE - PP block copolymer serves as a balanced surfactant for the highly immiscible PIB/PE blend in a manner that is analogous to the role of nonionic surfactants in oil/water mixtures. ${ }^{39-42}$ The present work on PE-PP/PIB mixtures represents the first step toward a quantitative understanding of balanced polymeric surfactants. We show that the phase behavior of $\mathrm{A}-\mathrm{B} / \mathrm{C}$ blends is determined by an intricate interplay between $\chi$ parameters and statistical segment lengths.

\section{Experimental Section}

A partially deuterated poly(ethylene-block-head-to-head propylene) copolymer (PE - PP) and a fully hydrogenous polyisobutylene (PIB) homopolymer were synthesized and characterized by methods described in refs $43-45$. The chemical structures of the polymers (ignoring the deuterium labels) are shown in Figure 1. The polymer characteristics are listed in Table 1. PE-PP/PIB blends were prepared by methods described in ref 46 . We discuss results obtained from a PE -PP/ PIB blend, labeled B25, which contains $25 \%$ block copolymer by volume.

Small-angle neutron scattering (SANS) measurements were conducted on a $1 \mathrm{~mm}$ thick sample encased between quartz windows on the $30 \mathrm{~m}$ beam line (NG3) at the National I nstitute of Standards and Technology in Gaithersburg, MD. The instrumental details are given in ref 47. Two-dimensional SANS data were measured as a function of scattering angles with the following instrument configuration: neutron wave length, $\lambda=12 \AA$, wavel ength spread, $\Delta \lambda / \lambda=0.15$, sampletodetector distance $=13.1 \mathrm{~m}$, sample aperture $=1.27 \mathrm{~cm}$, sourceto-sample distance $=14.7 \mathrm{~m}$, and source size $=5 \mathrm{~cm}$. The SANS patterns were corrected for background scattering, empty cell scattering, detector sensitivity, incoherent scattering, and converted to absolute scattering intensity using methods and secondary standards described in ref 48. Most of our discussion is based on the q dependence of the azimuthally averaged, coherent scattering intensity I $[q=4 \pi \sin (\theta)$ 2) $/ \lambda$ where $\theta$ is the scattering angle and $\lambda$ is the wavelength of the incident neutrons]. Some analysis of the 2-D SANS patterns without any corrections is also presented.

Small-angle light scattering (SALS) experiments were conducted on the same sample that was used in the SANS experiments. The instrumental details are given elsewhere. ${ }^{46}$ A beam of light with wavelength, $\lambda_{\text {light }}=633 \mathrm{~nm}$, from a 10 $\mathrm{mW}$ HeNe laser, was directed through the sample housed in a thermostated chamber. The scattered light in the angular range $2.5^{\circ}-10.7^{\circ}$ was focused onto a photodiode, corresponding to a $\mathrm{q}\left(=4 \pi \sin (\theta / 2) / \lambda_{\text {light }}\right)$ range of $4.33 \times 10^{-4}-1.85 \times 10^{-3}$ $\mathrm{nm}^{-1}$.

\section{Theory of Scattering from Homogeneous Mixtures}

In the random phase approximation (RPA), the coherent scattering intensity, I (q), from a single phase ( $n+$ 1) component polymer mixture, is given by ${ }^{11,49-52}$

$$
I(q)=\mathbf{B}^{\top} \underline{\underline{\mathbf{S}}}(q) \mathbf{B}
$$

We define a component to be a connected chain of identical monomers. $\underline{\mathbf{S}}(\mathrm{q})$ is an $\mathrm{n}$ by $\mathrm{n}$ structure factor matrix whose elements, $S_{i j}$, describe correlations be tween components $i$ and $j$. We assume that the mixture is incompressible, and this eliminates the correlations of one of the components (the "background" component). ${ }^{11,49}$ In our case the background component is PI B and is labeled 0 . Labels 1 and 2 refer to the PP and PE blocks in the PE - PP block copolymer, respectively. The column vector, B, has the following elements:

$$
B_{i}=\frac{b_{i}}{v_{i}}-\frac{b_{0}}{v_{0}} \quad(i=1,2)
$$

where $b_{i}$ is the scattering length of component $i$ and $v_{i}$ is the monomer volume of component $i$. The multicomponent structure factor matrix, $\underline{\underline{\mathbf{S}}}(\mathbf{q})$, is given in eq 3 :

$$
\underline{\underline{\mathbf{S}}}(q)=\left[\underline{\mathbf{S}}^{\circ}(q)^{-1}+\underline{\mathbf{V}}(q)\right]^{-1}
$$

where $\mathbf{S}^{\circ}(q)$ is the ideal structure factor matrix, describing correlations between the components in the absence of interactions, and $\mathbf{V}(q)$ is the interaction matrix. The elements of these $\overline{\bar{m}}$ atrices are

$$
\begin{gathered}
S_{i i}^{\circ}(q)=N_{i} \phi_{i} v_{i} P_{i}(q) \quad(i=1,2) \\
S_{12}^{\circ}(q)=S_{21}^{\circ}(q)=\left(N_{1} \phi_{1} v_{1} N_{2} \phi_{2} v_{2}\right)^{1 / 2} F_{1}(q) F_{2}(q)
\end{gathered}
$$




$$
\begin{array}{r}
\mathrm{v}_{\mathrm{ii}}(\mathrm{q})=\frac{1}{\mathrm{~N}_{0} \phi_{0} \mathrm{v}_{0} \mathrm{P}_{0}(\mathrm{q})}-\frac{2 \chi_{\mathrm{i} 0}}{\mathrm{v}} \quad(\mathrm{i}=1,2) \\
\mathrm{V}_{\mathrm{ij}}(\mathrm{q})=\frac{1}{\mathrm{~N}_{0} \phi_{0} \mathrm{v}_{0} \mathrm{P}_{0}(\mathrm{q})}-\frac{\chi_{\mathrm{i} 0}}{\mathrm{v}}-\frac{\chi_{\mathrm{j} 0}}{\mathrm{v}}+\frac{\chi_{\mathrm{ij}}}{\mathrm{v}} \quad(\mathrm{i} \neq \mathrm{j})
\end{array}
$$

where $\phi_{\mathrm{i}}$ is the volume fraction of component $\mathrm{i}$ in the blend, $\mathrm{N}_{\mathrm{i}}$ is the number of monomers per chain, $\chi_{\mathrm{ij}}$ is the Flory-Huggins interaction parameter between components $i$ and $j, v$ is a reference volume which we set equal to $100 \AA^{3}$, and

$$
\begin{gathered}
P_{i}(q)=\frac{2}{u_{i}^{2}}\left[\exp \left(-u_{i}\right)+u_{i}-1\right] \quad(i=0,1,2) \\
F_{i}(q)=\frac{1-\exp \left(-u_{i}\right)}{u_{i}} \quad(i=1,2)
\end{gathered}
$$

where $u_{i}=q^{2} R_{g i}{ }^{2}=q^{2} N_{i} l_{i}^{2} / 6$ and $R_{g i}$ is the radius of gyration of component $\mathrm{i}$.

Equations 1-6 are identical to those used in previous studies of multicomponent mixtures. ${ }^{33,36,37}$ The distinguishing feature of the present work is the presence of three chemically distinct components with qualitatively different $\chi_{\text {ij }}$ parameters.

\section{Theoretical Predictions for a Simplified A-B/C System}

A single-phase mixture is stable when the determinant of the structure factor matrix is positive: det[ $\mathbf{S}(q)]>0$. The stability limit (spinodal) of the single $\overline{\bar{p}}$ hase mixture is given by

$$
\operatorname{det}\left[\underline{\underline{\mathbf{S}}}\left(\mathrm{q}^{*}\right)\right]=0
$$

at any positive $\mathrm{q}^{*}$. If $\mathrm{q}^{*}$ in eq 7 is zero, it signals macrophase separation, while a finite value of $q^{*}$ indicates the formation of an ordered phase with a periodic length scale $\left(=2 \pi / q^{*}\right)$. In this study, temperature is used to destabilize the single-phase systems.

The thermodynamic behavior of $A-B / C$ mixtures is governed by six temperature-dependent variables: $\chi_{\mathrm{ij}}$ and $I_{i}(i, j=A, B$, or $C)$. It is not trivial to identify the subset of these parameters that governs the location of phase boundaries. We thus begin by computing results for a simplified model $A-B / C$ blend with the block copolymer volume fraction, $\phi=0.25$, characterized by the following parameters: all monomer volumes are equal to $v$ (the reference volume, $100 \AA^{3}$ ), and the chain lengths are such that $\mathrm{N}=\mathrm{N}_{\mathrm{A}}=\mathrm{N}_{\mathrm{B}}=2 \mathrm{~N}_{\mathrm{C}}$. These parameters mimic the experimental system. We al so set the Flory-Huggins interaction parameters and the statistical segment lengths such that $\chi_{\mathrm{AB}}=\chi_{\mathrm{AC}}=\chi_{,} \chi_{\mathrm{BC}}$ $=0$, and $\mathrm{I}_{\mathrm{A}}=\mathrm{I}_{\mathrm{C}}=1, \mathrm{I}_{\mathrm{B}}=\mathrm{I}$. The thermodynamics of our model system is thus dependent on two temperaturedependent parameters, $\chi$ and I, and one temperatureindependent parameter, $\mathrm{N}$. This is the simplest model block copolymer/homopolymer system wherein the homopolymer (C) has a (relative) attraction for the B block $\left(\chi_{\mathrm{BC}}=0\right)$ and all other interactions in the system are repulsive. The structure factor matrix, $\mathbf{S}(q)$, for our simplified A-B/C model system can readily be computed using eqs $3-6$ for a given set of $\chi, \mathrm{N}$, and I values. The spinodal locus ( $\chi$ vs I) was then obtained using eq 7 , for $\mathrm{N}$ values between 200 and 600 . When I <0.4, we obtain

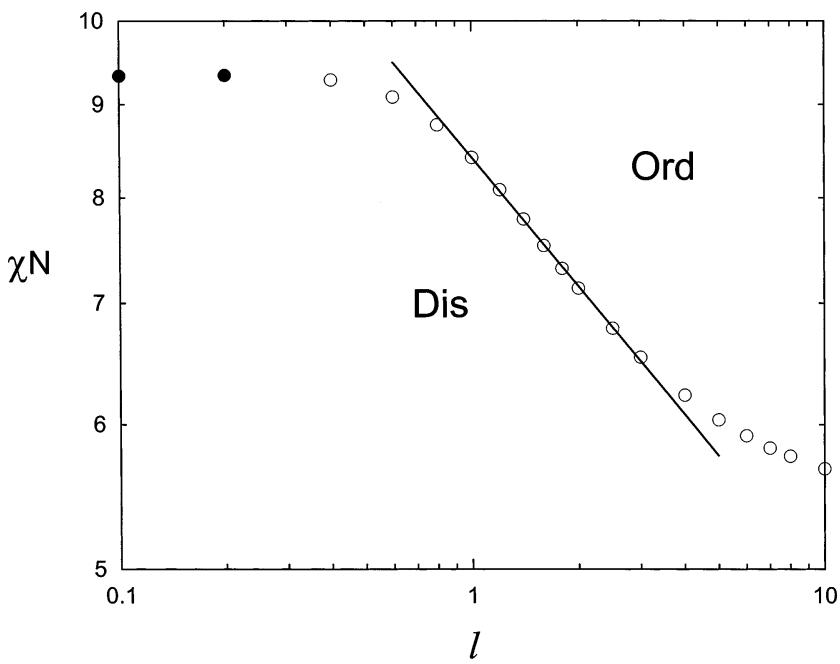

Figure 2. Spinodal locus for the model $A-B / C$ blend shown by plotting $\chi \mathrm{N}$ vs the statistical segment length of the $B$ block (I). The closed symbols represent the macrophase separation while the open symbols represent microphase separation. The line is the best fit of eq 8 through the $1.0 \leq \mathrm{I} \leq 3.0$ data.

macrophase separation, i.e., $\mathrm{q}^{*}=0$. At all other values of I we obtain microphase separation, i.e., $q^{*}>0$. While the nature of the phase separation was dependent on all three parameters $(\chi, \mathrm{N}, \mathrm{I})$, a single master curve was obtained when $\chi \mathrm{N}$ was plotted vs I. (We were unable to show analytically that $\chi$ and $\mathrm{N}$ always appear as a product in the equations that govern the spinodal, but all of our numerical calculations suggest that this is the case.) It is clear that the value of $\chi \mathrm{N}$ at which the phase transition occurs is a sensitive function of $I$, the statistical segment length of the block that has favorable interactions with C. When I is small compared to unity, a large value of $\chi \mathrm{N}$ (9.3 as shown in Figure 2 ) is required for phase separation. In contrast, when I is large compared unity, a small value of $\chi \mathrm{N}$ (5.7 as shown in Figure 2) is required for phase separation. At intermediate values of $I$ in the vicinity of unity (the most relevant case), $\chi \mathrm{N}$ is a steep function of I. A leastsquares power law fit through $1.0 \leq \mathrm{I} \leq 3.0$ gives

$$
\chi \mathrm{NI}^{0.235}=8.42
$$

The solid line in Figure 2 is eq 8 . Calculations for other blend compositions gave spinodal conditions that were qualitatively similar to eq 8.53

It is important to contrast eq 8 with the spinodal result for symmetric $A-B$ diblock copolymers with unequal statistical segment lengths $\left(\mathrm{N}_{\mathrm{A}}=\mathrm{N}_{\mathrm{B}}=\mathrm{N}, \mathrm{I}_{\mathrm{A}}\right.$ $=1, I_{B}=\mid>1$, which, in the range $1 \leq 1 \leq 2$, is approximately given by ${ }^{54}$

$$
\chi \mathrm{N}=5.268-0.134|+0.114|^{2}
$$

It is evident from eq 9 that for $A-B$ diblock copolymers the effect of inequality of statistical segment lengths leads to a small perturbative correction to the symmetric result. The ordered phase formed by a symmetric diblock copolymer is always lamellar, and it forms when $\chi \mathrm{N} \approx 5.25 .{ }^{16-18,33,55-57}$ I $\mathrm{n}$ contrast, for the case of $\mathrm{A}-\mathrm{B} / \mathrm{C}$ blends with repulsive and attractive interactions, the effect of unequal statistical segment lengths in $A-B / C$ mixtures cannot be expressed as an additive correction (eq 8). 

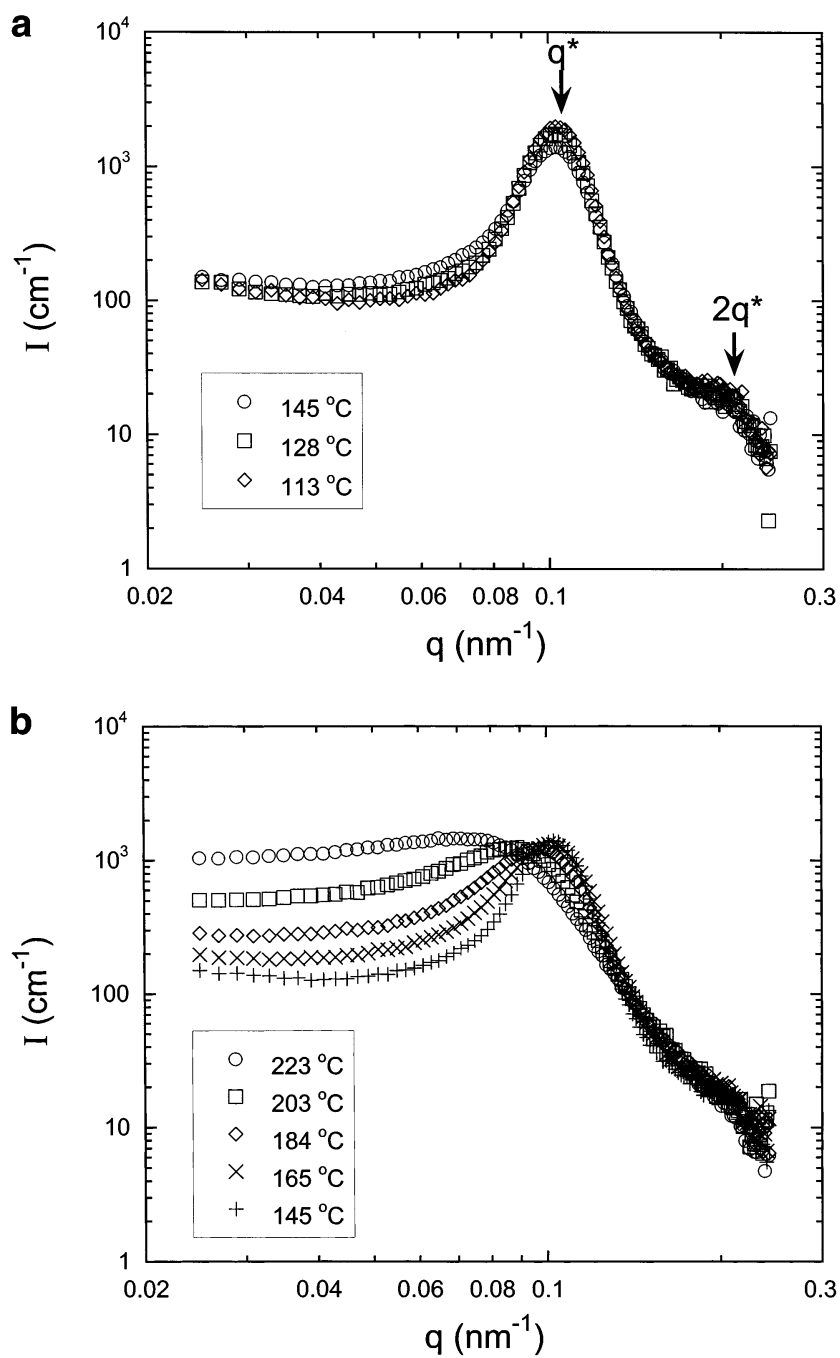

Figure 3. Temperature dependence of the coherent SANS intensity, I, as a function of the scattering vector, q, for B25 blend at selected temperatures. (a) For $113^{\circ} \mathrm{C} \leq \mathrm{T} \leq 145^{\circ} \mathrm{C}$, $\mathrm{q}^{*}$ denotes the primary peak position. (b) For $145^{\circ} \mathrm{C} \leq \mathrm{T} \leq$ $223^{\circ} \mathrm{C}$.

\section{Experimental Results and Discussion}

In Figure 3 we show the temperature dependence of the coherent SANS intensity, I(q), obtained from B25. The sample temperature was increased in a stepwise manner from 113 to $223{ }^{\circ} \mathrm{C}$. I n Figure 3a, we show I (q) obtained at temperatures $\leq 145{ }^{\circ} \mathrm{C}$. The scattering profiles are virtually independent of temperature in this temperature range. We see a primary scattering peak at $\mathrm{q}^{*}=0.103 \mathrm{~nm}^{-1}$ and a weak second-order peak at $\mathrm{q}$ $\approx 2 q^{*}$, indicating the presence of a lamellar phase. The formation of flat interfaces in our blend is surprising because of its composition and the nature of the intermolecular interactions. The blend contains PEPP block copolymer volume fraction of 0.25 , which, in the $113{ }^{\circ} \mathrm{C} \leq \mathrm{T} \leq 145{ }^{\circ} \mathrm{C}$ range, exhibits attractive interactions with the PP block and repulsive interactions with the PE block. ${ }^{38}$ Thus, if we assume for simplicity that the PIB chains reside exclusively in the PP microdomains, the lamellae in our blend would be highly asymmetric with alternating $7.6 \mathrm{~nm}$ PE and 53.4 $\mathrm{nm}$ PP + PIB layers. In conventional systems such as pure diblock copolymers and A-B/A blends, the ordered phase formed under such asymmetric conditions would undoubtedly be spherical.23,55 However, we note that, in their study of multicomponent blends with attractive

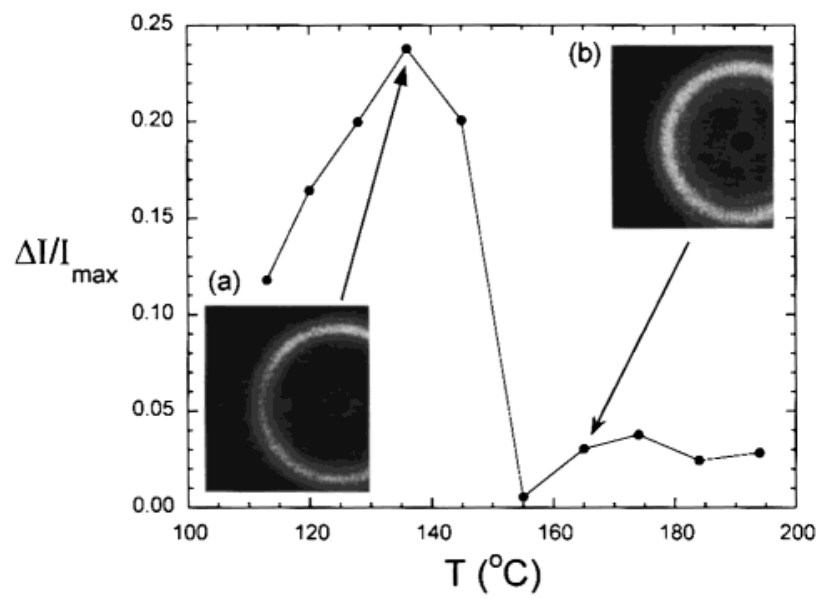

Figure 4. 2-D SANS profiles at (a) 136 and (b) $165{ }^{\circ} \mathrm{C}$. Temperature dependence of $\Delta \mathrm{I} / \mathrm{I}_{\max }$, where $\Delta \mathrm{I}$ is the difference between the maximum and minimum intensity of scattering in the ring ( $I_{\text {ring }}$ ) seen in parts (a) and (b), and $I_{\max }$ is the maximum value of $\mathrm{I}_{\text {ring. }}$. An abrupt change in $\Delta \mathrm{I} / \mathrm{I}_{\max }$ at $\mathrm{T} \approx$ $150{ }^{\circ} \mathrm{C}$ signifies the order-disorder transition.

and repulsive interactions, J amieson et al. also reported the formation of phase-inverted structures and flat interfaces in highly asymmetric blends. ${ }^{30}$ It thus appears that the factors that govern the phase behavior of systems with both attractive and repulsive interactions are qualitatively different from those seen in diblock copolymers and A-B/A blends.

In Figure $3 b$ we show SANS profiles obtained at temperatures $\geq 145^{\circ} \mathrm{C}$. It is clear from a comparison of F igure $3 a, b$ that the temperature dependence of I (q) at temperatures above $145^{\circ} \mathrm{C}$ is dramatically different from that below $145^{\circ} \mathrm{C}$. The scattering peak in Figure 3b moves toward smaller q with increasing temperature. In addition, there is a substantial increase in the low-q scattering; I $\left(\mathrm{q}=0.031 \mathrm{~nm}^{-1}\right)$ increases by an order of magnitude when the temperature is changed from 145 to $223{ }^{\circ} \mathrm{C}$. The weak second-order peak seen at low temperatures (Figure 3a) disappears at the higher temperatures, suggesting the absence of an ordered phase in this temperature range.

At temperatures $\leq 145^{\circ} \mathrm{C}$, we found that the SANS patterns from our PE -PP/PIB blend were azimuthally anisotropic. An example of such a profile is shown in Figure 4a where we show 2-D SANS data obtained at $136^{\circ} \mathrm{C}$. In contrast, the SANS profiles at temperatures $\geq 155^{\circ} \mathrm{C}$ were isotropic. An example of such a profile is shown in Figure $4 \mathrm{~b}$ where we show 2-D SANS data obtained at $165^{\circ} \mathrm{C}$. The orientation of block copolymer lamellae can easily be perturbed by small forces such as those required to press the sample between the quartz disks. This often results in an anisotropic distribution of lamellar orientations, which leads to anisotropy in the SANS profiles. Thus, the presence of azimuthally anisotropic SANS profiles is an indication of the presence of an anisotropic ordered phase (e.g., a lamellar phase). ${ }^{58}$ In ref 37 we determined the orderdisorder transition temperature of pure PE-PP (the same block copolymer used in this study) to be $149.5 \pm$ $1.5{ }^{\circ} \mathrm{C}$ by noting the temperature at which the azimuthal anisotropy was lost.

To quantify the temperature range over which anisotropic scattering profiles were observed, we calculated $I_{\text {ring, }}$, the integrated intensity in a scattering ring around the peak defined by $\mathrm{q}^{*} \pm 0.03 \mathrm{~nm}^{-1}$, and computed the difference between the highest $\left(I_{\max }\right)$ and lowest $\left(I_{\min }\right)$ 

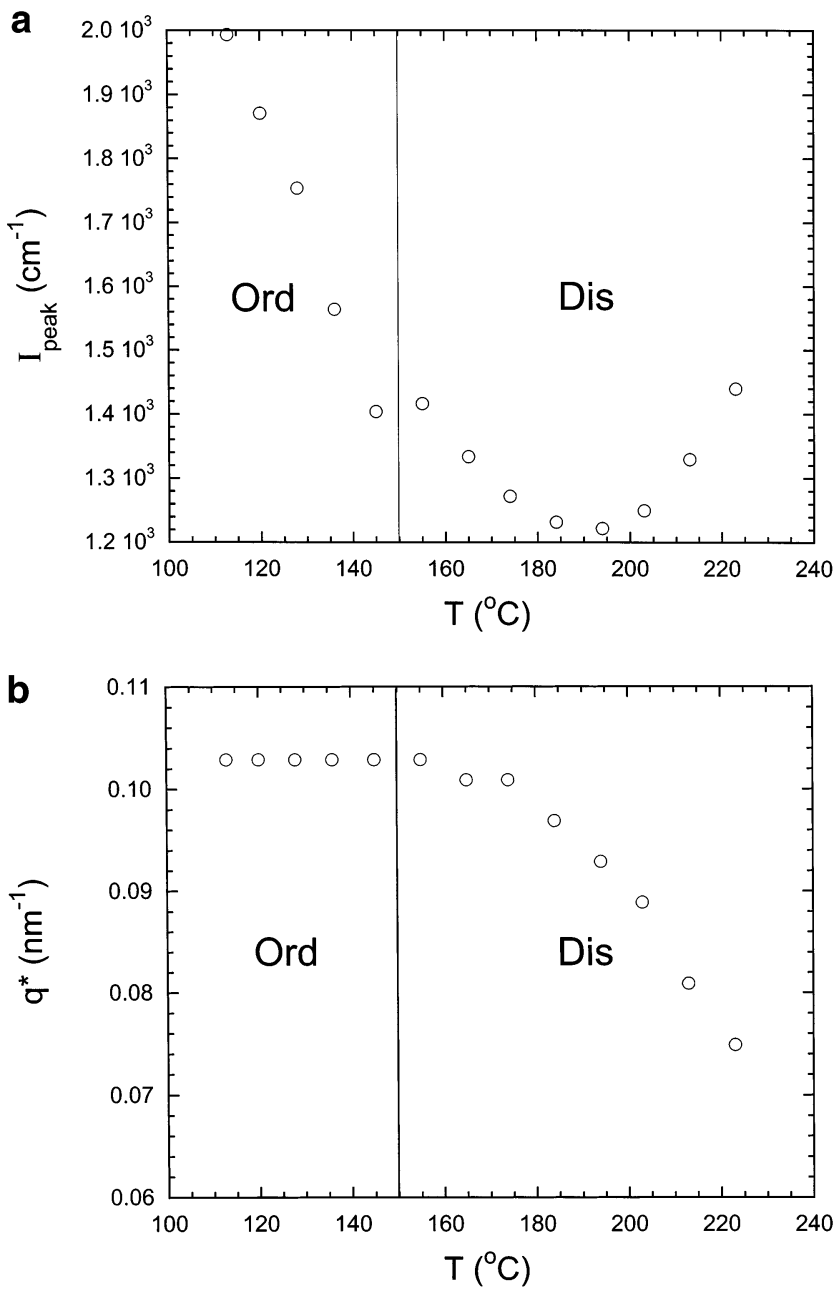

Figure 5. Temperature dependence of (a) SANS intensity at the scattering peak, I peak, and (b) wave vector at scattering maximum, q*. "Ord" and "Dis" indicate the ordered and disordered regimes, respectively, and the vertical line indicates the order-disorder transition.

values of $I_{\text {ring, }} \Delta I\left[\Delta I=I_{\max }-I_{\min }\right]$. In Figure 4 we plot the dimensionless quantity $\Delta \mathrm{I} / \mathrm{I}_{\max }$ as a function of temperature. The abrupt decrease in the magnitude of $\Delta \mathrm{I} / \mathrm{I}_{\max }$ at $150{ }^{\circ} \mathrm{C}$ indicates that the order-disorder transition temperature of our PE-PP/PIB blend is 150 $\pm 5{ }^{\circ} \mathrm{C}$. This assignment is consistent with that based on the disappearance of the higher order peak at 165 ${ }^{\circ} \mathrm{C}$ (see Figure $\left.3 a, b\right)$.

We now examine the temperature dependence of the main features of the SANS profiles from our blend. In Figure 5a we show the temperature dependence of $I_{\text {peak. }}$. We see an approximately linear temperature dependence of $I_{\text {peak }}$ in the ordered state, denoted "Ord". An abrupt jump in I peak is evident at $150^{\circ} \mathrm{C}$ (vertical line). In contrast, nonmonotonic behavior is seen in the disordered state, denoted "Dis". Since an increase in scattering intensity suggests proximity to a phase transition, the nonmonotonic temperature dependence of $I_{\text {peak }}$ in the homogeneous phase indicates the possibility of two phase transitions. In Figure $5 b$ we plot the temperature dependence of $q^{*}$. In the $T \geq 155^{\circ} \mathrm{C}$ regime, $q^{*}$ decreases with increasing temperature, indicating a substantial increase in the characteristic length of the concentration fluctuations. At thelamellae to-disorder transition $\left(150^{\circ} \mathrm{C}\right)$ the characteristic length scale is $61 \mathrm{~nm}$, while at $223^{\circ} \mathrm{C}$ the length scale increases to $84 \mathrm{~nm}$.

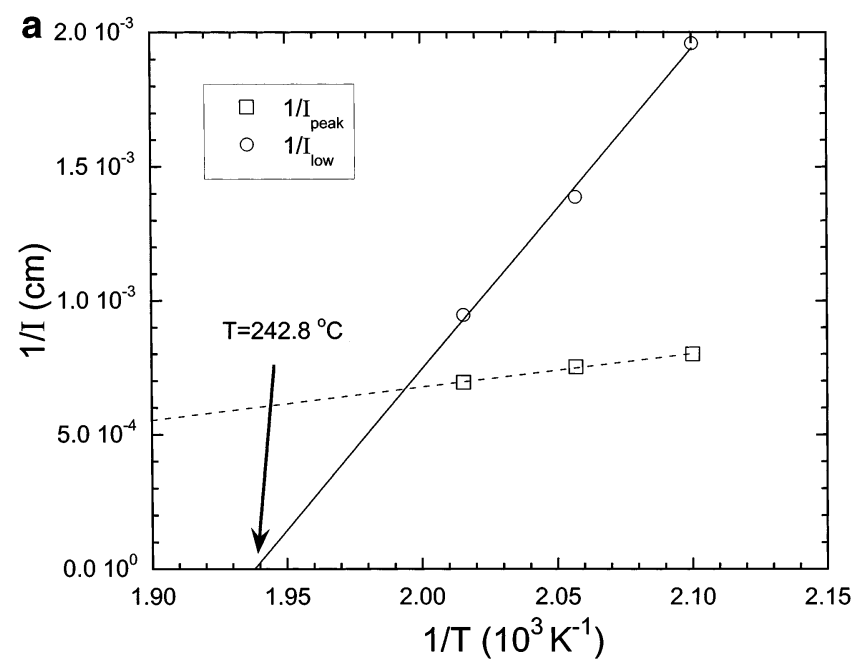

b

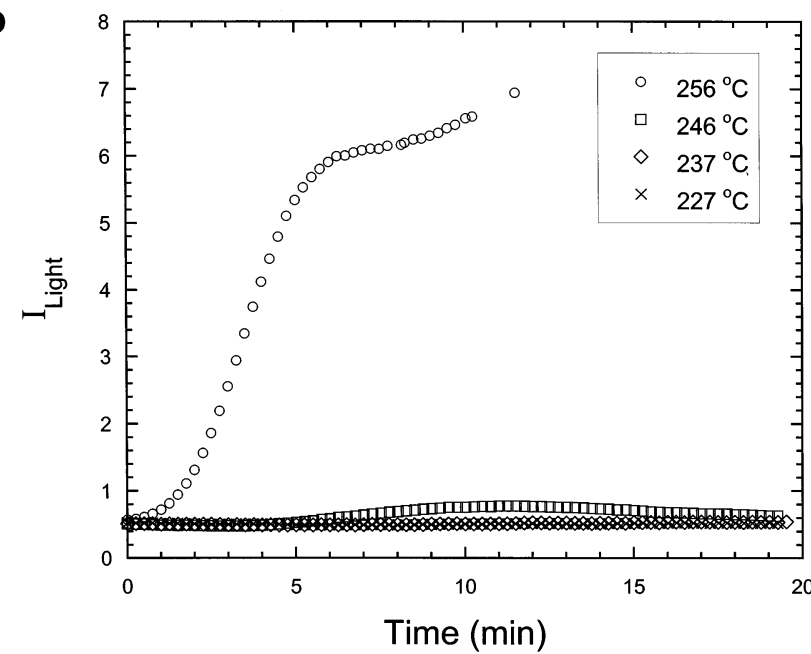

Figure 6. (a) Temperature dependence of SANS intensities $I_{\text {peak }}$ and $I_{\text {low. }}($ b) The small-angle light scattering intensity vs time after step changes in sample temperature as indicated. Both sets of data indicate macrophase separation at about 245 ${ }^{\circ} \mathrm{C}$.

The scattering profiles from our blend at high temperatures (Figure $3 b$ ) are characterized by a scattering peak and significant forward scattering. This indicates the coexistence of periodic concentration fluctuations as well as nonperiodic, large length scale concentration fluctuations. Such a system can, in principle, exhibit either microphase or macrophase separation. To distinguish between these possibilities, we examine the temperature dependence of scattering intensity at the lowest accessible $q, I_{\text {low }}=I\left(q=0.031 \mathrm{~nm}^{-1}\right)$ and $I_{\text {peak }}$. In Figure $6 a$ we plot $1 / l_{\text {low }}$ vs $1 / T$. The temperature at which $\mathrm{I}_{\text {low }}$ is predicted to diverge is $243{ }^{\circ} \mathrm{C}$ (see solid line in Figure 6a). This is well below the temperature where the divergence of $I_{\text {peak }}$ is expected (see dashed line in Figure 6a). Even though $I_{\text {peak }}$ is greater than $I_{\text {low }}$ in the entire range of the SANS experiments, the rapid increase in $I_{\text {low }}$ with temperature, relative to $I_{\text {peak, }}$, is indicative of a macrophase separation transition at 243 ${ }^{\circ} \mathrm{C}$.

To establish the macrophase-separated state of the blend in the vicinity of $243{ }^{\circ} \mathrm{C}$, we conducted light scattering experiments. The blend was annealed for 2 $\mathrm{h}$ at $174{ }^{\circ} \mathrm{C}$ in the disordered state (see Figure $3 \mathrm{~b}$ ), and scattered light was monitored as a function of time after a stepwise increase in sample temperature. In Figure $6 \mathrm{~b}$ we plot light scattering intensity vs time for a series 
of temperature steps. At temperatures lower than 237 ${ }^{\circ} \mathrm{C}$, the sample is entirely transparent, and there was no change in the light scattering signal. When the sample temperature was changed from 237 to $246{ }^{\circ} \mathrm{C}$, a slight increase in the signal was observed, indicating proximity to the macrophase separation temperature. The next temperature step from 246 to $256^{\circ} \mathrm{C}$ led to a dramatic increase in the scattered light, and the sample appeared visibly cloudy. This macrophase transition temperature, determined by light scattering to be 251 $\pm 5^{\circ} \mathrm{C}$, is in reasonable agreement with the extrapolated SANS data which indicated macrophase separation at $243{ }^{\circ} \mathrm{C}$. The fact that the observed light scattering increase occurs where the SANS intensity at low q diverges suggests that the high-temperature macrophase separation observed in our PE-PP/PIB blend is a second order (or weakly first order) phase transition.

We now interpret the scattering profiles in the disordered state using the RPA (eqs 1-6). The determination of the Flory-Huggins interaction parameters $(\chi)$ and statistical segment lengths $(I)$ is described in the Appendix. A comparison between the RPA fits and experimental data in the homogeneous state is shown in Figure 7. The experimentally measured peak positions, peak intensities, and high $q\left(q>q^{*}\right)$ scattering are in quantitative agreement with the RPA fits. We also see a noticeable increase in low q scattering beginning at $\mathrm{T}=184{ }^{\circ} \mathrm{C}$ in both theory and experiment (Figure 7). The only quantitative disagreement is that the theoretical increase in low angle scattering $\left(q<q^{*}\right)$ with increasing temperatures $\left(T \geq 184^{\circ} \mathrm{C}\right)$ is less than that observed experimentally.

In Figure 8 we show the temperature dependence of $\chi_{\mathrm{PE} / \mathrm{PP},} \chi_{\mathrm{PE} / \mathrm{PIB}}$, and $\chi_{\mathrm{PP} / \mathrm{PIB}}$, obtained by the fitting procedure described in the Appendix. All of the $\chi$ parameters show the usual temperature dependence $(\chi=\mathrm{A}+$ $\mathrm{B} / \mathrm{T})$. The solid lines are the least-squares fit through the data, which yield

$$
\begin{aligned}
& \chi_{\mathrm{PE} / \mathrm{PP}}=9.55 \times 10^{-3}+1.02 / \mathrm{T} \\
& \chi_{\mathrm{PE} / \mathrm{PIB}}=2.57 \times 10^{-3}+4.99 / \mathrm{T} \\
& \chi_{\mathrm{PP} / \mathrm{PIB}}=1.08 \times 10^{-2}-5.04 / \mathrm{T}
\end{aligned}
$$

In contrast, the results from SANS experiments of binary homopolymer blends (where PE and PP chains were partially deuterated, as is the case in this work) gave the following expressions for the interaction parameters: ${ }^{37,38}$

$$
\begin{gathered}
\chi_{\mathrm{PE} / \mathrm{PP}}^{\mathrm{b}}=-1.80 \times 10^{-2}+11.0 / \mathrm{T} \\
\chi_{\mathrm{PP} / \mathrm{PIB}}^{\mathrm{b}}=1.80 \times 10^{-2}-7.7 / \mathrm{T}
\end{gathered}
$$

It is evident from eqs 10-14 and the Appendix that the interactions in our PE-PP/PIB blend are significantly different from those in binary blends. These differences are well outside simple corrections due to finite polydispersity of the polymers. ${ }^{59}$

In Figure 9, we show the temperature dependence of the statistical segment lengths obtained by the fitting procedure described in the Appendix. Both the absolute magnitudes of $I_{P E}$ and $I_{P P}$ and their changes with temperature given in Figure 9 are similar to that

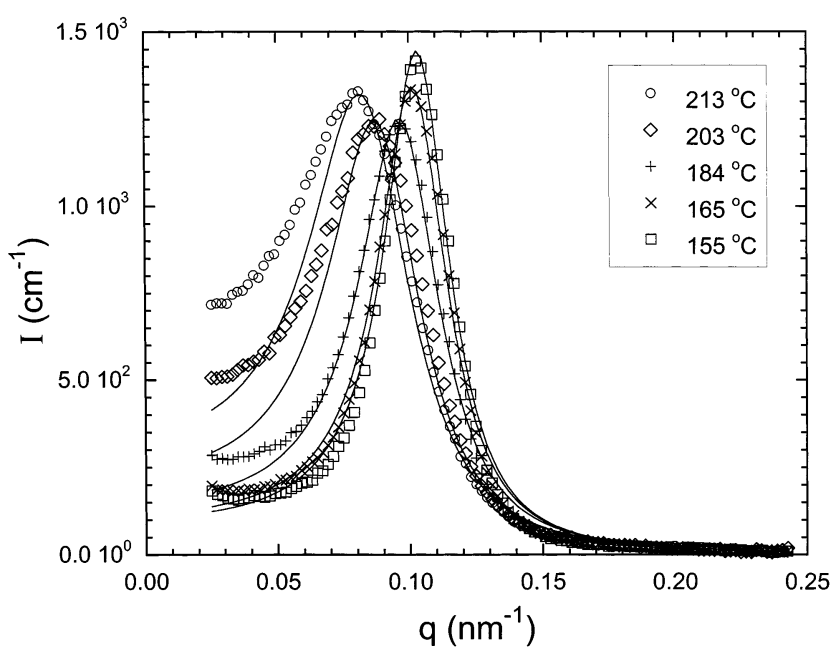

Figure 7. SANS intensity $I$ as a function of $q$ at selected temperatures in the disordered state. The solid curves are the RPA-based fits.
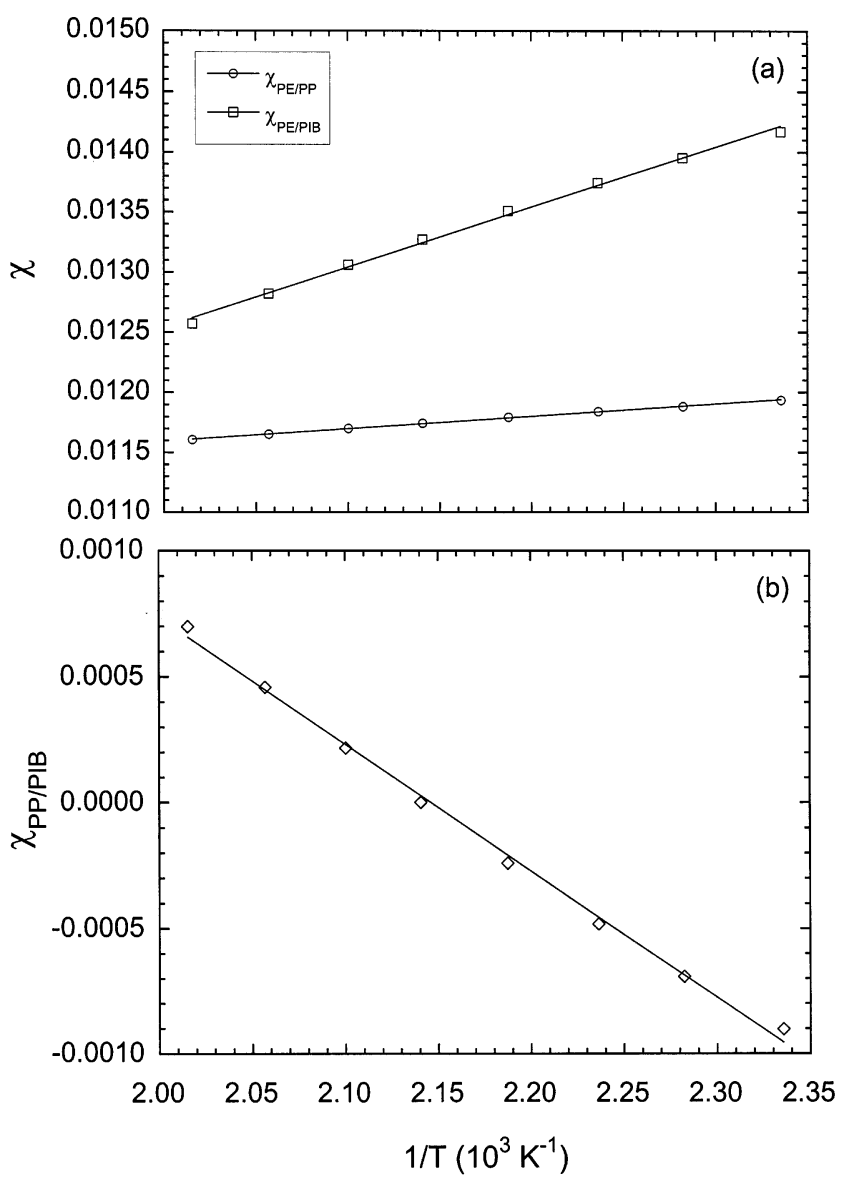

Figure 8. Temperature dependence of the Flory-Huggins interaction parameters, $\chi_{i j}$, determined by fitting the PE $-P P /$ PIB SANS data to the RPA-based predictions. The estimated error in the interaction parameters is about $10 \%{ }^{64}$

obtained in binary PE/PP blends. ${ }^{37}$ The IPIB $_{\text {value in our }}$ $\mathrm{PE}-\mathrm{PP} / \mathrm{PIB}$ blend is significantly larger than that obtained from binary PIB/PP blends (see Table 3 in Appendix), and $I_{P I B}$ is a stronger function of $T$, relative to $I_{P E}$ and $I_{P P}$. It is interesting to note that rather simple temperature dependencies of $\chi_{i j}$ and $I_{i}$ shown in Figures 8 and 9 combine to produce complex nonmonotonic SANS profiles obtained in the disordered state (see Figure 7). 


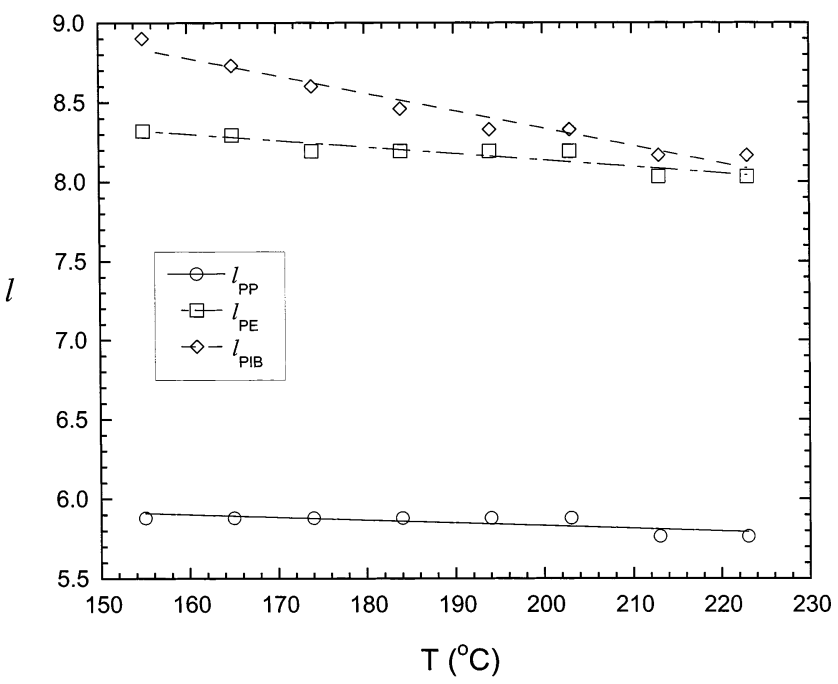

Figure 9. Temperature dependence of the statistical segment lengths, $I_{i}$, of the components in the PE-PP/PIB blend. The estimated error in the statistical segment lengths is about $10 \%{ }^{64}$

Table 2. Effect of Parameters on Low-Temperature Ordering Transition ${ }^{a}$

\begin{tabular}{cccccc}
\hline$\chi_{\mathrm{PE} / \mathrm{PIB}}$ & $\chi_{\mathrm{PP} / \mathrm{PIB}}$ & $\chi_{\mathrm{PE} / \mathrm{PP}}$ & $\mathrm{I}_{\mathrm{PE}}$ & $\mathrm{I}_{\mathrm{PP}}$ & $\mathrm{I}_{\mathrm{PIB}}$ \\
\hline+ & - & - & - & + & -
\end{tabular}

a + implies bringing the system close to the ordering transition, and - implies taking the system away from the ordering transition.

Table 3. Parameters Used for RPA Calculations at 223 ${ }^{\circ} \mathbf{C}^{\mathbf{a}}$

\begin{tabular}{lcccl}
\hline components & $\mathrm{N}_{\mathrm{i}}$ & $\mathrm{v}_{\mathrm{i}}\left(\AA^{3}\right)$ & $\mathrm{b}_{\mathrm{i}}\left(\times 10^{4} \AA\right)$ & $\mathrm{N}_{\text {deu }}$ \\
\hline $\mathrm{dPE}-\mathrm{dPP}$ & & & & \\
dPE & 590 & 120.70 & 2.32 & 3.77 \\
dPP & 542 & 126.69 & 3.59 & 2.55 \\
PIB & 256 & 114.24 & -0.332 & 0
\end{tabular}

a All parameters are based on a $\mathrm{C}_{4} \mathrm{H}_{8}$ monomer unit. $\mathrm{N}_{\mathrm{i}}$ and $\mathrm{v}_{\mathrm{i}}$ denote the number of monomers per chain and monomer volume, respectively. The monomer volumes are calculated based on densities of each homopolymer at $296 \mathrm{~K}: \mathrm{V}_{\mathrm{PP}, 0}=104.50 \AA^{3}, \mathrm{~V}_{\mathrm{PE}, 0}$ $=109.25 \AA^{3}$, and $V_{P I B, 0}=101.52 \AA^{3}$. The thermal expansion coefficients, $\alpha_{i}$, used in this calculation are $7.2 \times 10^{-4} \mathrm{~K}^{-1}, 7.4 \times$ $10^{-4} \mathrm{~K}^{-1}$, and $5.9 \times 10^{-4} \mathrm{~K}^{-1}$ for PP, PE, and PIB, respectively. $b_{i}$ and $\mathrm{N}_{\text {deu }}$ denote the scattering length density and the number of deuterium in a monomer unit. Other details are given in ref 37.

It is impossible to ascertain the uniqueness of the $\chi$ and I parameters given in Figures 8 and 9 . Even in the simple case of $A-B$ diblock copolymers, unique values for the statistical segment lengths of both blocks cannot be determined from SANS data. While many groups assume that the statistical segment lengths of both blocks are identical, 55,60 it is well-known that other combinations of the statistical segment lengths give equally good fits. ${ }^{60}$ We tried a number of approaches for arriving at the $\chi$ and I parameters (other than that described in the Appendix). None of the approaches gave significantly better fits than those shown in Figure 7. In addition, the other procedures gave complex, nonmonotonic (and often unphysical) temperature dependencies for $\chi$ and I parameters. The parameters given in Figures 8 and 9 thus represent the simplest set of parameters that explain the main features of the scattering data shown in Figure 7.

To study the nature of phase transitions in our system, we extrapolated the temperature dependencies of the six parameters, $\chi_{i j}$ and $I_{i}$ shown in Figures 8 and

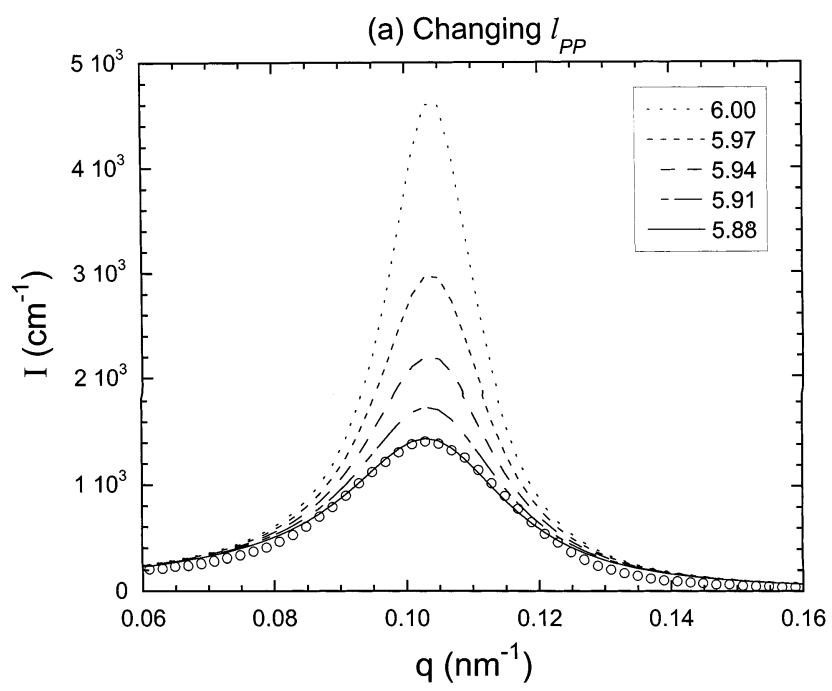

(b) Changing $\chi_{\mathrm{PE} / \mathrm{PP}}$

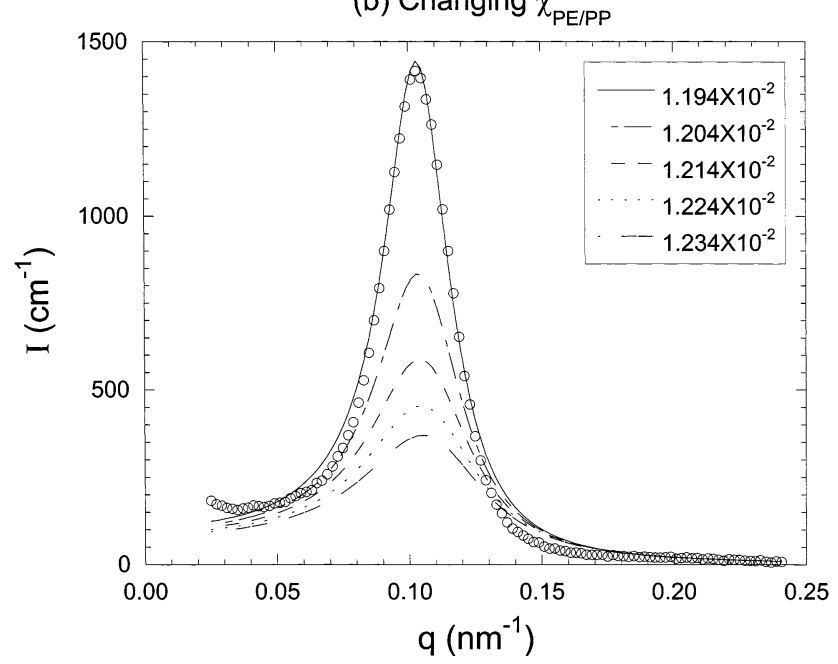

Figure 10. RPA-based scattering profiles as a function of (a) $I_{\text {PP }}$ and (b) $\chi_{\text {PE/PP. }}$. The values of all other parameters were kept fixed at their values at $155^{\circ} \mathrm{C}$. The symbols are the measured SANS profiles at $155^{\circ} \mathrm{C}$.

9, and computed I (q). The calculated scattering profile at $\mathrm{T}=145^{\circ} \mathrm{C}$ shows an unphysical singularity (pole) at $\mathrm{q}=0.107 \mathrm{~nm}^{-1}$, which indicates microphase separation at a temperature between 155 and $145^{\circ} \mathrm{C}$. This is, in fact, what is observed experimentally (see Figure 3 ). It is thus evident that the RPA captures the main features of the low-temperature phase transition. Extrapolation of the lines in Figures 8 and 9 to high temperatures leads to scattering profiles with singularities at $\mathrm{q}=0.067 \mathrm{~nm}^{-1}$ (at $\mathrm{T} \geq 231^{\circ} \mathrm{C}$ ), indicating microphase separation. This result is in conflict with experiments that indicate that the high-temperature phase is macrophase-separated. This lack of agreement is related to the inability of the RPA to correctly predict the low-angl e scattering from our PE-PP/PIB blend at high temperatures (see Figure 7).

The six parameters shown in Figures 8 and 9 can either stabilize or destabilize the homogeneous phase in our PE-PP/PIB mixture. This is illustrated in Figure 10. In Figure 10a we show the measured SANS profile at $155^{\circ} \mathrm{C}$ (symbols) and RPA-based calculations (curves) of I (q), keeping all of the $\chi$ and I parameters fixed at their value at $155{ }^{\circ} \mathrm{C}$ except Ipp. We find that the calculated scattering intensity diverges as $I_{p p}$ is increased from 5.88 to $6.00 \AA$ (note that Ipp increases with 


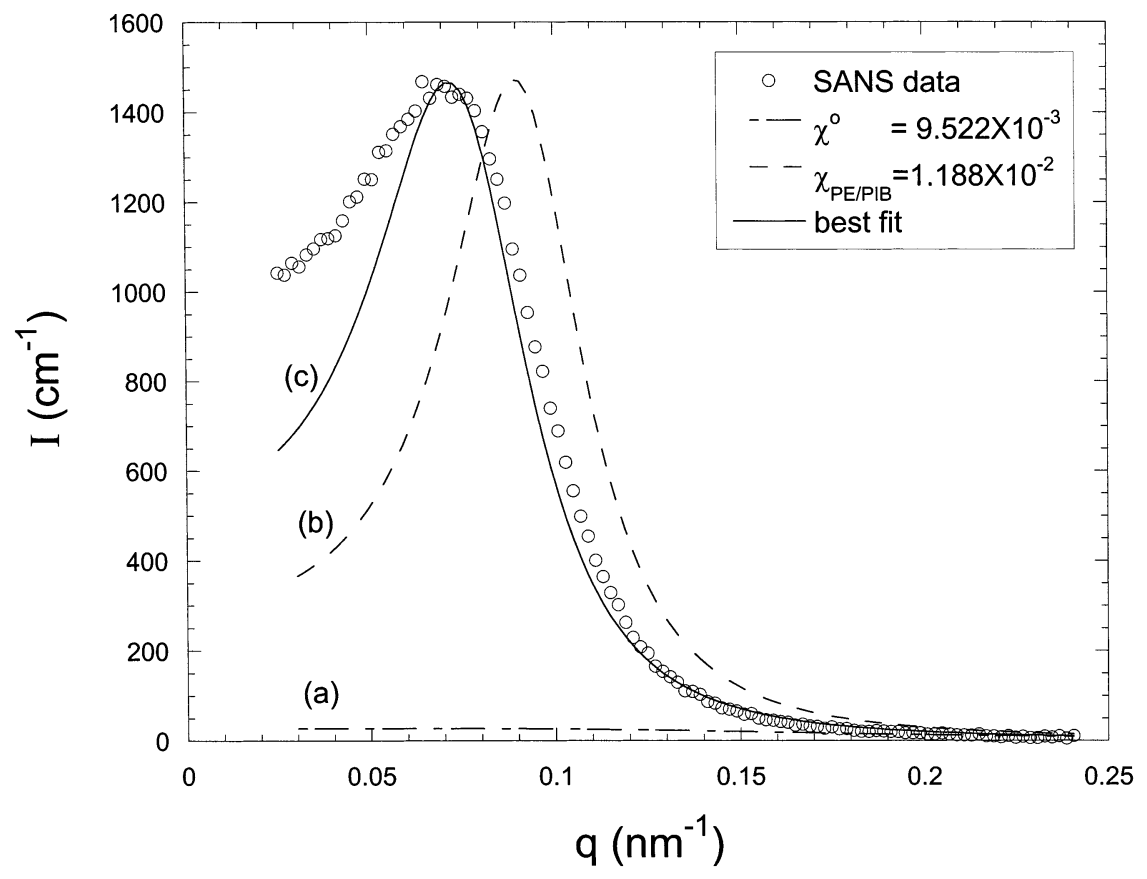

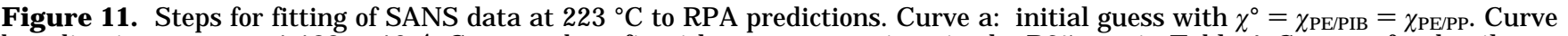
b: adjusting $\chi_{\mathrm{PE} / \mathrm{PIB}}$ to $1.188 \times 10^{-4}$. Curve c: best fit with parameters given in the B25 row in Table 4 . See text for details.

decreasing temperature; see Figure 9). In Figure 10b where we show the results of RPA calculations as a function of increasing $\chi_{\mathrm{PE} / \mathrm{PP}}$, keeping all other parameters fixed at their value at $155^{\circ} \mathrm{C}$. It is evident that the calculated intensity decreases with increasing $\chi \mathrm{PE} / \mathrm{PP}$. The surprising conclusion is that increasing the repulsion between the PE and PP blocks suppresses microphase separation in the PE-PP/PIB mixture.

We conducted the analysis described in Figure 10 on the remaining four parameters ( $\chi_{\mathrm{PE} / \mathrm{PIB}}, \chi_{\mathrm{PP} / \mathrm{PIB}}, \mathrm{I}_{\mathrm{PE}}$, and $\left.I_{P P}\right)$ and determined the change of I peak when these parameters were changed along the trajectories described in Figures 8 and 9. Our results are summarized in Table 2 where a positive sign indicates that the parameter brings the system closer to microphase separation (increase in $I_{\text {peak }}$ ), while a negative sign indicates that the parameter takes the system away from microphase separation (decrease in I peak). Only $\chi_{\mathrm{PE} / \mathrm{PIB}}$ and IPP are responsible for the microphase separation transition at $150{ }^{\circ} \mathrm{C}$. It is evident that the location of the phase boundaries of our PE-PP/PIB blend depends on a complex combination of the inherent interactions between chains and the statistical segment lengths. In this sense, the PE-PP/PIB blend is similar to the model calculations for the $A-B / C$ blend where we found that the phase boundary location was governed by the product $\chi \mathrm{NI}^{0.235}$ (see Figure 2 and eq 8). Much more work is required to obtain similar equations for the phase boundaries of PE-PP/PIB blends because they will involve a multitude of $\chi_{\mathrm{ij}}, \mathrm{I}_{\mathrm{i}}$, and $\mathrm{N}_{\mathrm{i}}$ parameters.

\section{Conclusions}

Concentration fluctuations and phase behavior of a blend of poly(ethylene-block-head to head propylene) (PE-PP) and polyisobutylene (PIB) with PE-PP volume fraction of 0.25 were studied using small-angle neutron scattering (SANS) and small-angle light scattering (SALS). The PE-PP/PIB blend is characterized by three rather different interactions: PE and PIB are highly incompatible polymers, and PE and PP are somewhat incompatible, while PIB and PP exhibit attractive interactions $(\chi<0)$ at low temperatures and repulsive interactions $(\chi>0)$ at high temperatures. Our blend exhibits an order-disorder transition at $150 \pm 5$ ${ }^{\circ} \mathrm{C}$ and macrophase separation at $251 \pm 5{ }^{\circ} \mathrm{C}$. At intermediate temperatures $\left(155^{\circ} \mathrm{C}<\mathrm{T}<246^{\circ} \mathrm{C}\right)$, the blend is a homogeneous, disordered mixture. We obtain "effective" interaction parameters and statistical segment lengths by fitting multicomponent RPA results to the experimental data in this temperature range. The complex, nonmonotonic temperature dependencies of the scattering profiles are consistent with statistical segment lengths and interaction parameters that have simple, monotonic temperature dependencies.

The thermodynamic properties of our PE-PP/PIB blend are governed by six temperature-dependent parameters $\left(\chi_{\mathrm{PE} / \mathrm{PIB}}, \chi_{\mathrm{PE} / \mathrm{PP}}, \chi_{\mathrm{PP} / \mathrm{PIB}}, \mathrm{I}_{\mathrm{PE}}, \mathrm{I}_{\mathrm{PP}}\right.$, and $\left.\mathrm{I}_{\mathrm{PIB}}\right)$. We examined the effect of all six parameters on the lowtemperature microphase transition using the RPAbased calculations. We found that the observed divergence of the scattered intensity is due to two parameters, $\chi_{\mathrm{PE} / \mathrm{PIB}}$ and IPP. Changes in the other parameters (including an increase in $\chi_{\mathrm{PE} / \mathrm{PP}}$ ) lead to a suppression of scattering intensity. It is evident that the immiscibility between PE and PIB chains and the statistical segment length of the PP block are primary factors governing the low-temperature ordering transition. Similar analysis of the high-temperature macrophase separation could not be carried out due to a breakdown of the RPA.

The stability limit of $A-B / C$ blends with both attractive and repulsive interactions display an unusual sensitivity to both statistical segment lengths and interaction parameters. We showed, using RPA calculations on a simplified $\mathrm{A}-\mathrm{B} / \mathrm{C}$ blend, characterized by a single $\chi$ parameter and two statistical segment lengths (unity and I), that the phase boundary is governed by the magnitude of the product of $\chi \mathrm{N}^{0.235}$. Deriving quantitative relationships for the phase boundary of blends such as PE-PP/PIB is significantly more challenging due to the multitude of parameters that are 
Table 4. Interaction Parameters and Statistical Segment Lengths in B25 at $223^{\circ} \mathrm{C}$

\begin{tabular}{lllcccc}
\hline & $\begin{array}{c}\chi_{\mathrm{PE} / \mathrm{PP}} \\
\left(\times 10^{2}\right)\end{array}$ & $\begin{array}{c}\chi_{\mathrm{PE} / \mathrm{PIB}} \\
\left(\times 10^{2}\right)\end{array}$ & $\begin{array}{c}\chi_{\mathrm{PP} / \mathrm{PIB}} \\
\left(\times 10^{2}\right)\end{array}$ & $\mathrm{I}_{\mathrm{PE}}$ & $\mathrm{I}_{\mathrm{PP}}$ & $\mathrm{I}_{\mathrm{PIB}}$ \\
\hline binary & 0.4171 & & 0.24 & 7.38 & 5.92 & 6.27 \\
B25 & 1.161 & 1.257 & 0.07 & 8.03 & 5.76 & 8.17
\end{tabular}

involved. This paper represents the first step toward developing such relationships.

Acknowledgment. Financial support provided by the NSF (CTS-0196066 and DMR-9875321) is gratefully acknowledged. The SANS instrument is supported by Grant DMR-9986442 from the National Science Foundation to NIST.61

\section{Appendix: Details of Fitting the Experimental Data to the RPA-Based Theory}

We illustrate our fitting procedure by using the data obtained at $223^{\circ} \mathrm{C}$. Parameters obtained from polymer characterization $-N_{i}, v_{i}$, and $b_{i}$-are given in Table 3 . The values of $\chi_{i j}^{b}$ and $I_{i}^{b}$ (we use the superscript $b$ to denote parameters in binary homopolymer mixtures) at $223^{\circ} \mathrm{C}$, obtained from previous measurements on binary homopolymer blends, are given under the heading "binary" in Table 4. 37,38,62 The only parameter that is

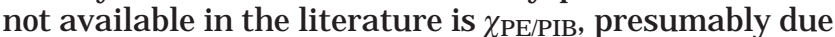
to the extreme incompatibility of PE and PIB chains. We thus varied $\chi_{\mathrm{PE} / \mathrm{PIB}}$ over the entire range of possible values, i.e., where the computed I(q) was real and positive for all $q \geq 0$. All values of $\chi_{P E / P I B}$ lead to monotonic scattering profiles while the SANS data indicate the presence of a peak. It is thus impossible to capture the essential features of our PE-PP/PIB blend at $223{ }^{\circ} \mathrm{C}$ by changing $\chi_{\mathrm{PE} / \mathrm{PIB}}$ alone. (All other parameters are taken from binary measurements.)

Since the PP/PIB interactions lead to lower critical solution temperature (LCST) behavior and the $\chi$ parameters in these systems are often composition dependent (e.g., refs 7 and 12), we changed both $\chi_{\mathrm{PE} / \mathrm{PIB}}$ and $\chi_{\text {PP/PIB }}$ over the range where the computed I (q) was real and positive for all $\mathrm{q} \geq 0$. We found that changing both $\chi_{\text {PE/PIB }}$ and $\chi_{\text {PP/PIB }}$ also led to monotonic scattering profiles. We thus conclude that the thermodynamics of PE - PP/PIB mixtures cannot be predicted on the basis of binary parameters $\left(\chi_{i j}^{b}\right.$ and $\left.I_{i}^{b}\right)$ alone.

We thus needed to vary all three $\chi$ parameters $\left(\chi_{\mathrm{PE} / \mathrm{PP} \text {, }}\right.$ $\chi_{\mathrm{PE} / \mathrm{PIB}}$, and $\left.\chi_{\mathrm{PP} / \mathrm{PIB}}\right)$ and all three statistical segment lengths $\left(I_{P E}, I_{P P}\right.$, and $\left.I_{P I B}\right)$ to obtain reasonable agreement with the data. In our initial excursions, we used the binary values for the statistical segment lengths (given in the binary row of Table 3 ) and assumed that $\chi_{\mathrm{PE} / \mathrm{PIB}}=\chi_{\mathrm{PE} / \mathrm{PP}}=\chi^{\circ}$. (This only provides an initial guess for these parameters.) To obtain scattering profiles with peaks, we found that $\chi^{\circ}$ has to be increased and $\chi_{\text {PP/PIB }}$ has to be decreased from their binary values. The result of $\chi^{\circ}=9.522 \times 10^{-3}$ and $\chi_{\mathrm{PP} / \mathrm{PIB}}=2.340 \times 10^{-4}$ gives the lowest curve labeled (a) in Figure 11. Since we know that $\chi_{\mathrm{PE} / \mathrm{PIB}}$ is larger than $\chi_{\mathrm{PE} / \mathrm{PP}}{ }^{63}$ we increased $\chi_{\mathrm{PE} / \mathrm{PIB}}$. We find that the agreement between the experimental data and the RPA-based scattering curves improves when this is done, as shown in Figure 11. We adjusted the magnitude of $\chi_{\text {PE/PIB }}$ until we were able to get a good fit of the experimental peak intensities $\left(1417 \mathrm{~cm}^{-1}\right.$ as seen in Figure 11). This occurred at $\chi_{\mathrm{PE} / \mathrm{PIB}}=1.188 \times$ $10^{-2}$, and the resulting curve is labeled (b) in Figure 11.
The last step of the fitting procedure consists of minor adjustments of the parameters to obtain a theoretical curve that matches as many of the experimental features as possible. We found that changing all of the statistical segment lengths by a fixed multiplicative factor leads to a change of peak position without affecting the peak height. We thus obtain new estimates of $\mathrm{I}_{i}$ by matching the observed and calculated peak position. It was found that there is significant difference between fitted theoretical curve and experiment at low $q\left(q<q^{*}\right)$. We increased $\chi_{P E / P I B}$ to minimize this difference, but this caused increases in both $I_{\text {peak }}$ as well as high $q$ scattering $\left(q>q^{*}\right)$. Changing $I_{P E}$ and $I_{P I B}$ enabled compensation of these increases. We found that increasing IPE $_{\mathrm{P}}$ alone decreases the scattering intensity in the high $q$ portion of the scattering peak $\left(q>q^{*}\right)$, while increasing $I_{P I B}$ alone decreased the peak height. Thus, after $\chi \mathrm{PE} / \mathrm{PIB}$ was increased to match the low $\mathrm{q}$ data, $I_{P E}$ and $I_{P I B}$ were changed so that there was agreement between theory and experiment in the vicinity of the peak and in the $q>q^{*}$ region. The $\chi_{P E / P I B}$, $I_{P E}$, and $I_{P I B}$ adjustments were repeated until the deviation between theoretical and experimental curves was minimized. The best fit thus obtained is indicated by the solid curve, label ed (c) in Figure 11. The agreement between theory and experiment is considerably better at lower temperatures, as shown in Figure 7.

\section{References and Notes}

(1) Paul, D. R., Bucknall, C. B., Eds.; Polymer Blends; J ohn \& Wiley: New York, 2000.

(2) de Gennes, P. G. Scaling Concepts in Polymer Physics; Cornell University Press: Ithaca, NY, 1979.

(3) Herktmaetzky, C.; Schelten, J . Phys. Rev. Lett. 1983, 51, 896.

(4) Hadziioannou, G.; Stein, R. S. Macromolecules 1984, 17, 567.

(5) Okada, M.; Han, C. C. J . Chem. Phys. 1986, 85, 5317.

(6) Hashimoto, T.; I takura, M.; Hasegawa, H. J . Chem. Phys. 1986, 85, 6118 .

(7) Han, C. C.; Bauer, B.J .; Clark, J . C.; Muroga, Y.; Matsushita, Y.; Okada, M.; Qui, T. C.; Chang, T. H.; Sanchez, I. C. Polymer 1988, 29, 2002.

(8) Bates, F. S.; Wiltzius, P. J . Chem. Phys. 1989, 91, 3258.

(9) Balsara, N. P.; Fetters, L. J .; Hadjichristidis, N.; Lohse, D. J .; Han, C. C.; Graessley, W. W.; Krishnamoorti, R. Macromolecules 1992, 25, 6137.

(10) Schwahn, D.; J anssen, S.; Springer, T. J . Chem. Phys. 1992 97, 8775.

(11) Hammouda, B. Adv. Polym. Sci. 1993, 106, 87.

(12) Krishnamoorti, R.; Graessley, W. W.; Balsara, N. P.; Lohse, D. J . J . Chem. Phys. 1994, 100, 3894.

(13) Kielhorn, L.; Muthukumar, M. J . Chem. Phys. 1997, 107, 5588.

(14) Fredrickson, G. H.; Helfand, E.J . Chem. Phys. 1987, 87, 697.

(15) de Gennes, P. G. J . Phys., Lett. 1997, 38, 441.

(16) Leibler, L. Macromolecules 1980, 13, 1602.

(17) Vavasour, J . D.; Whitmore, M. D. Macromol ecules 1996, 29, 5244.

(18) Vavasour, J . D.; Whitmore, M. D. Macromol ecules 1993, 26, 7070.

(19) Bates, F. S.; Schulz, M. F.; Rosedale, J. H.; Almdal, K. Macromolecules 1992, 25, 5547.

(20) Matsen, M. W.; Schick, M. Macromolecules 1994, 27, 4014.

(21) Matsen, M. W.; Bates, F. S. Macromol ecules 1996, 29, 1091.

(22) J eon, K.J .; Roe, R. J . Macromolecules 1994, 27, 2439.

(23) Winey, K. I.; Gobran, D. A.; Xu, Z. D.; Fetters, L. J .; Thomas, E. L. Macromolecules 1994, 27, 2392.

(24) Lowenhaupt, B.; Hellmann, G. P. Polymer 1991, 32, 1065.

(25) Lowenhaupt, B.; Steurer, A.; Hellmann, G. P.; Gallot, Y. Macromolecules 1994, 27, 908.

(26) Koizumi, S.; Hasegawa, H.; Hashimoto, T. Makromol . Chem. Macromol. Symp. 1992, 62, 75.

(27) Iizuka, N.; Bodycomb, J .; Hasegawa, H.; Hashimoto, T. Macromol ecules 1998, 31, 7256.

(28) Hashimoto, T.; Kimishima, K.; Hasegawa, H. Macromolecules 1991, 24, 5704 
(29) Hashimoto, T.; Izumitani, T.; Oono, K. Makromol. Chem. Macromol. Symp. 1995, 98, 925.

(30) Adedeji, A.; J amieson, A. M.; Hudson, S. D. Macromolecules 1995, 28, 5255.

(31) Washburn, N. R.; Lodge, T. P.; Bates, F. S. J . Phys. Chem. B 2000, 104, 6987.

(32) Hillmyer, M. A.; Maurer, W. W.; Lodge, T. P.; Bates, F. S.; Almdal, K. J . Phys. Chem. B 1999, 103, 4814.

(33) Lin, C. C.; J onnalagadda, S. V.; Balsara, N. P.; Han, C. C.; Krishnamoorti, R. Macromol ecules 1996, 29, 661.

(34) Lin, C. C.; J eon, H. S.; Balsara, N. P.; Hammouda, B. J . Chem. Phys. 1995, 103, 1957.

(35) Lee, J. H.; Balsara, N. P.; Krishnamoorti, R.; J eon, H. S.; Hammouda, B. Macromol ecules 2001, 34, 6557.

(36) J eon, H. S.; Lee, J. H.; Balsara, N. P.; Newstein, M. C. Macromol ecules 1998, 31, 3340.

(37) J eon, H. S.; Lee, J . H.; Balsara, N. P. Macromolecules 1998, 31, 3328.

(38) Krishnamoorti, R.; Graessley, W. W.; Fetters, L. J .; Garner, R. T.; Lohse, D. J . Macromolecules 1995, 28, 1252.

(39) Kahlweit, M.; Strey, R.; Firman, P.; Haase, D. Langmuir 1985, 1, 281.

(40) Kahlweit, M.; Strey, R. Angew. Chem., Int. Ed. Engl. 1985, 24,654

(41) Kahlweit, M.; Strey, R.; Haase, D.; Firman, P. Langmuir 1988, 4, 785.

(42) Magid, L.; Butler, P.; Payne, K.; Strey, R. J . Appl . Crystallogr. 1988, 21, 832.

(43) Storey, R. F.; Chisholm, B. J .; Brister, L. B. Macromolecules 1995, 28, 4055

(44) Morton, M.; Fetters, L. J . J . Rubber Chem. Technol. 1975, $48,359$.

(45) Rachapudy, H.; Smith, G. G.; Raju, V. R.; Graessley, W. W. J . Polym. Sci., Polym. Phys. 1979, 17, 1211.

(46) J eon, H. S.; Lee, J.H.; Balsara, N. P.; Majumdar, B.; Fetters, L. J .; Faldi, A. Macromolecules 1997, 30, 973.

(47) Hammouda, B.; Krueger, S.; Glinka, C. J . J . Res. Natl. Inst. Stand. Technol. 1993, 98, 31

(48) Balsara, N. P.; J onnalagadda, S. V.; Lin, C. C.; Han, C. C.; Krishnamoorti, R. J . Chem. Phys. 1993, 99, 10011.

(49) Akcasu, A. Z.; Tombakoglu, M. Macromolecules 1990, 23, 607

(50) Akcasu, A. Z.; Klein, R.; Hammouda, B. Macromolecules 1993, $26,4136$.

(51) Benoit, H.; Benmouna, M.; Wu, W. L. Macromolecules 1990, 23, 1511.
(52) Leibler, L. Makromol. Chem., Rapid Commun. 1981, 2, 393.

(53) A least-squares power law fit through the data in Figure 2 gave an exponent of 0.235 . The exponents obtained for other blend compositions were slightly different, e.g. for $\phi=0.5$, the exponent was 0.260 , and the prefactor was 6.11 .

(54) In these calculations we assume that monomers and interaction parameters are defined on the basis of a fixed reference volume $v=100 \AA^{3}$.

(55) Bates, F. S.; Schulz, M. F.; Khandpur, A. K.; Forster, S.; Rosedale, J . H.; Almdal, K.; Mortensen, K. Faraday Discuss. 1994, 98, 7.

(56) Forster, S.; Khandpur, A. K.; Zhao, J .; Bates, F. S.; Hamley, I. W.; Ryan, A. J .; Bras, W. Macromolecules 1994, 27, 6922.

(57) Calculations show that the theoretical phase diagram be comes skewed when $\mid \neq 1$ and nonlamellar phases are sometimes predicted, but the experimental phase diagrams for a symmetric block copolymer always shows an ordered lamellar phase.

(58) Bates, F. S.; Rosedale, J. H.; Fredrickson, G. H. J . Chem. Phys. 1990, 92, 6255.

(59) The effect of finite polydispersity on the thermodynamics of the PE-PP copolymer used in this study is reported in ref 37. The difference between the $\chi$ parameters determined using the monodisperse and poldisperse structure factors was less than $10 \%$.

(60) Lin, C. C.; J onnalagadda, S. V.; Kesani, P. K.; Dai, H. J .; Balsara, N. P. Macromolecules 1994, 27, 7769.

(61) NIST does not necessarily endorse the products and chemicals named in this paper

(62) Hayashi, H.; Flory, P. J .; Wignall, G. D. Macromol ecules 1983, $16,1328$.

(63) We have conducted light scattering experiments on PE/PP and PE/PIB mixtures of similar molecular weights and find that the PE/PP mixtures are homogeneous while the PE/PIB mixtures are highly phase separated at the same temperatures.

(64) The major factors that lead to errors in interpreting SANS experiments are (1) errors in absolute calibration, (2) instrumental smearing of scattering profiles, and (3) errors in measurement of polymer molecular weight $\left(\mathrm{N}_{\mathrm{i}}\right)$ and deute rium content $\left(\mathrm{b}_{\mathrm{i}}\right)$. Assuming that the errors are not correlated, we expect the error in the interaction parameters and the statistical segment lengths to be about $10 \% .^{9,33}$

MA020361U 